\title{
A Preliminary Study: Comparative Toxicity of Extracts from Tinospora tuberculata Beumee and Lumnitzera racemosa Willd on Aedes aegypti Linnaeus Larvae (Diptera: Culicidae)
}

\begin{abstract}
A. A. WAHIZATUL ${ }^{1 *}$ AND R. SHASITA ${ }^{1}$
Research has been widely made on the potential use of herbal plants as effective agents for mosquito vector control. However, only a few studies have been carried out to investigate the potential insecticidal activity of mangrove plants against these dengue vectors. This study was carried out to examine the comparative toxicity of two mangrove plants, Tinospora tuberculata and Lumnitzera racemosa against the Aedes aegypti larvae. The leaf and stem of T. tuberculata and L. racemosa, were extracted using $95 \%$ methanol and these extracts bioassayed against the 3 rd instar larvae of aegypti under laboratory conditions. The $\mathrm{LC}_{50}$ values of the crude extract of $T$. tuberculata stem and leaf were $0.5778 \mathrm{mg} / \mathrm{ml}$ and $0.7213 \mathrm{mg} / \mathrm{ml}$, respectively. For L. racemosa, the $\mathrm{LC}_{50}$ value for stem was $1.2833 \mathrm{mg} / \mathrm{ml}$ and $1.1957 \mathrm{mg} / \mathrm{ml}$ for leaf. However, no significant differences in toxicity were detected for the stem and leaf of both plants. Both plants, especially T. tuberculata might contain insecticidal components toxic to larvae of Ae aegypti.
\end{abstract}

Key words: Toxicity; Tinospora tuberculata; Lumnitzera racemosa; Aedes aegypti; herbal plants; mosquito vector; dengue vectors

Some mosquitoes are known to transmit many serious diseases to humans. Among these mosquitoes, the commonest genus that bites humans are Anopheles, Culex, Aedes, Mansonia, Haemogogus, Sebethes and Psorophora. In Malaysia, there are 381 species in 20 genera of mosquitoes, some of which are medically important vectors of arboviruses (Ken et al. 2002).

The principal mosquito vector that transmits the arbovirus of dengue is Aedes aegypti. The dengue (Flaviviridae) virus is arguably the most important arbovirus affecting humans (Curtis 1986). Dengue fever and dengue hemorrhagic fever are caused by one of four closely related but antigenically distinct virus serotypes, DEN-1 DEN-2 DEN-3 and DEN-4. Infection by one of these serotypes provides immunity to only that serotype for life, so people living in a dengue-endemic area could have more than one dengue infection during their lifetime (Glubber 1989).

The incidence of dengue has attained levels that are of considerable concern to local authorities. Until today, there are no effective dengue vaccines available. The only way of decreasing the incidence of the disease is the suppression of Ae. aegypti. Experience has shown that spraying of chemical insecticides against this mosquito was not effective, since

\footnotetext{
${ }^{1}$ School of Marine Science and Environment, Universiti Malaysia Terengganu, 21030 Kuala Terengganu, Terengganu, Malaysia.

*Corresponding author (e-mail: wahizatul@umt.edu.my)
} 
it was highly domesticated and many adults rested indoors in hidden places such as closets. One of the possible ways of reducing mosquito densities to a level where dengue epidemics did not occur was to control the immature stage. Therefore, systematic treatment of the breeding places using larvicide could be effective.

In recent years, the use of environmentally friendly and biodegradable agents of plant origin has received renewed interest for disease vector control (Alkofahi et al. 1989). They are potentially suitable for use in integrated vector management programmes as the selective pressure imposed by conventional insecticides was enhancing resistance in mosquito populations. Today, over 2000 species of plants that possess some insecticidal activity are known (Jacobson 1989). The demand for new products that are environmentally safe, target-specific, and degradable enhance interest for natural products. Considerable effort has been focused on plant derived material for potentially suitable useful products such as commercial insecticides. The first compound that was used extensively against adult mosquitoes was the flower extract of Chrysanthemum cinerariaefolium (Senthil et al. 2005). Plant derived chemicals also show some potential in reducing the biological activities of insects rather than synthetic insecticides. For example, the oil extracts from Cinnamomun pubescens, C. micropyllum and Litsea elliptice (Family: Lauraceae) show effective larvicidal activity (Wong 2001). Other plants such as Bougainvillea glabra (Family: Nyctaginaceae) also have the potential as pesticides (Thangam \& Kathiresan 1990).

Considering the large number of plants that are reputed to possess some form of insecticidal activity, only a few local plants have been scientifically evaluated. In this current study, we were interested in examining the potential insecticidal activity of the herbal plant, Tinospora tuberculata (Ranunculales:
Menispermaceae) and the mangrove plant, Lumnitzera racemosa (Angiospermacea: Combretaceae) on 3rd instar Ae. aegypti larvae. There have been very few studies focused on T. tuberculata and L. racemosa as insecticides or pesticides (Thangam \& Kathiresan 1990; Lee \& Hishamudin 1990). We chose L. racemosa as this mangrove plant was abundantly found in Terengganu. Furthermore, some studies have reported that the fruit, bark and flower of L. racemosa have been used as treatment for asthma, diabetes and snake bite (Premanathan et al. 1992). Attempts also have been made to compare the different toxicity effects of crude extract from the leaf and stem of both plants. The outcome of the study could hopefully contribute to the discovery of an alternative bioinsecticide for the control of Ae. aegypti larvae.

\section{MATERIALS AND METHODS}

\section{Sample Collection and Extraction}

T. tuberculata was collected from an area around Wakaf Tembusu in Terengganu, whereas L. racemosa was obtained from a mangrove area near the nursery of Universiti Malaysia Terengganu (UMT). The plant material according to the part needed, were crushed into small particles and dried at room temperature $\left(\sim 27^{\circ} \mathrm{C}\right)$. Dried plant particles were ground into powder separately. $100 \mathrm{~g}$ of the powder from each needed part of the plant were mixed with $1000 \mathrm{ml}$ of methanol (95\%) and stirred for 3 days in a stirrer machine. Filtration was done on the suspension using Whatman No.1 filter paper and filter funnel into a beaker. The filtered solution was placed into a flask and concentrated by evaporation using a low pressure rotary evaporator at $40^{\circ} \mathrm{C}-45^{\circ} \mathrm{C}$. Extractions were done until all the solvent was evaporated leaving the solid crude. The crude extract was stored in a beaker covered with aluminum foil at $20^{\circ} \mathrm{C}$ for future bioassay. The same process was done for all needed parts of both plants. 


\section{Preparation of Stock Solution and Test Concentrations}

Stock solutions of extracts from both plants were prepared with concentrations of $50 \mathrm{mg} / \mathrm{ml}$. These were obtained by diluting $5 \mathrm{~g}$ of crude extract in $100 \mathrm{ml}$ of solvent ( $1 \%$ of DMSO). The stock solution was then serially diluted, in triplicate, with distilled water to prepare test solutions of $2 \mathrm{mg} / \mathrm{ml}, 1 \mathrm{mg} / \mathrm{ml}, 0.500 \mathrm{mg} / \mathrm{ml}$, $0.250 \mathrm{mg} / \mathrm{ml}$ and $0.125 \mathrm{mg} / \mathrm{ml}$ crude extract. Sterile water was used to dilute the crude extract and preparation of the dilutions of leaf and stem for each plant species were the same using the method as above.

\section{Aedes aegypti Larvae}

Eggs of Ae. aegypti were obtained from the insectarium of the Unit of Medical Entomology, Institute for Medical Research, Malaysia. Larvae of Ae. aegypti were obtained by placing a filter paper with dried mosquito eggs into a tray filled with water. The eggs were left for 1 $\mathrm{h}$ to $48 \mathrm{~h}$ to hatch. One teaspoon of dried ox liver powder was added into the container as larval food once the eggs had hatched. The larvae were maintained at room temperature $\left(27^{\circ} \mathrm{C} \pm 2{ }^{\circ} \mathrm{C}\right)$ and at a relative humidity of between $75 \%-85 \%$. The water in the container that was used to rear the larvae was changed frequently to ensure that it was clean and clear. The container was covered with muslin cloth to ensure that other mosquitoes did not lay eggs into the tray.

\section{Bioassay Procedure}

Bioassays were performed on the late $3 \mathrm{rd}$ or early 4th instar larvae of Ae. aegypti. One hundred $\mathrm{ml}$ of test solutions of five different concentrations were prepared. At each concentration, 10 larvae were tested. In control runs, $100 \mathrm{ml}$ of distilled water without the extract was prepared. The treatments were replicated three times and each replicate set contained one control. Experiments were conducted at room temperature $\left(\sim 27^{\circ} \mathrm{C}\right)$, photoperiods of $12 \mathrm{~h}$ light followed by $12 \mathrm{~h}$ dark $(12 \mathrm{~L}: 12 \mathrm{D})$ and at a relative humidity of $75 \%-85 \%$. Mortality counts were made after $24 \mathrm{~h}$ of exposure. In the analysis, both dead and moribund larvae were considered as dead, whereas numbers of live larvae were counted separately.

\section{Statistical Analysis}

Data obtained from the bioassay toxicity test were analysed by probit analysis (Finney 1971). Probit analysis was used to calculate the confidence intervals for dose-response quantiles $\left(\mathrm{LC}_{50}\right)$. One-way ANOVA was used to compare the toxicity of leaf and stem crude extract for each part of plants studied. The data was $\log (x+1)$ transformed to ensure normality in calculations of means and ANOVAs. If the control mortality was below 20\%, Abbott's formula was used (World Health Organization 1981). However, in tests where the control mortality was above $20 \%$, the experiment was discarded.

\section{RESULTS}

The $\mathrm{LC}_{50}$ of the leaf extract of $T$. tuberculata was $0.7213 \mathrm{mg} / \mathrm{ml}$ against third instar Ae. aegypti larvae. In comparison, the $\mathrm{LC}_{50}$ of the stem was $0.5778 \mathrm{mg} / \mathrm{ml}$ against Ae. aegypti larvae. There was no mortality observed in the controls. In this experiment, there was no significant difference detected between the leaf and stem of the herbal plant, T. tuberculata $(p=0.2396)$.

The $\mathrm{LC}_{50}$ value for stem and leaf of L. racemosa was $1.2833 \mathrm{mg} / \mathrm{ml}$ (for stem) and $1.1957 \mathrm{mg} / \mathrm{ml}$ (for leaf). There was no mortality observed in the controls and no significant difference between the leaf and stem of the mangrove plant, L. racemosa was detected $(p=0.2430)$. 
Table 1 summarizes the lethal concentration of extract (LC50) for each part of plants against the $3 \mathrm{rd}$ instar Ae. aegypti larvae. The insecticidal activity of stem and leaf of T. tuberculata was higher $(0.5778 \mathrm{mg} / \mathrm{ml}$ and $0.7213 \mathrm{mg} / \mathrm{ml})$ than the stem and leaf extraction of $L$. racemosa $(1.2833 \mathrm{mg} / \mathrm{ml}$ and $1.1957 \mathrm{mg} / \mathrm{ml}$ ). However, the variance between leaf and stem of $T$. tuberculata showed no significant difference $(p=0.2370)$. Similarly, no significant difference between the leaf and stem of $L$. racemosa was detected ( $p=0.243)$.

\section{DISCUSSION}

Even though there were no significant differences between the leaf and stem for each plant, both plants showed the presence of certain insecticidal chemical compounds. The study suggests that both $T$. tuberculata and L. racemosa did have compounds which exhibited insecticidal activity on the target insect. Both T. tuberculata and L. racemosa plants exhibited different levels of toxic effect on third instar Ae. aegypti larvae. T. tuberculata exhibited higher toxicity compared to L. racemosa against the $3 \mathrm{rd}$ instar Ae. aegypti larvae. However, no significant differences of $\mathrm{LC}_{50}$ values were detected between leaf and stem of T. tuberculata. For L. racemosa, both stem and leaf exhibited $\mathrm{LC}_{50}$ values of $1.2833 \mathrm{mg} / \mathrm{ml}$ and $1.1957 \mathrm{mg} / \mathrm{ml}$, respectively. Similarly, both $\mathrm{LC}_{50}$ values of leaf and stem of $L$. racemosa showed no significant differences.
The results showed that extracts of $T$. tuberculata stem greatly affected the growth of Ae. aegypti larvae compared to extracts from the leaf. Generally, higher concentrations of each part of $T$. tuberculata affected the larvae development and did have a significant impact on the mortality of the larvae. We found most of the larvae exhibited abnormal and erratic movements, dying before reaching the pupal stage when they were exposed to higher concentrations of T. tuberculata. The bioactivity of phytochemicals from plants against mosquito larvae could vary significantly depending on the plant species, plant part, age of plant part, solvent used in extraction and mosquito species (Essam et al. 2004). Presumably, the toxicity effect exhibited by both plants indicated possible bioactive compounds that were engaged in insecticidal response. Plants from family Menispermaceae had been identified to exhibit pharmaceutical properties and also as insecticides (Essam et al. 2004). Previous studies using plants from family Menispermaceae had obtained very good toxicity effects on Ae. aegypti larvae. For example, Stephania japonica, which was distributed widely in Ulu Anap, Sarawak secondary forest, had been identified to have antimalarial properties (Ibuka et al. 1967). Although the toxicity effect possessed by T. tuberculata was much lower than other plants from family Menispermacea, the experiment had proved that the plant exhibited insecticidal activity. Tinospora tuberculata contained insecticidal phytochemicals that

Table 1. $\mathrm{LC}_{50}$ values for crude extract of stem and leaf of Tinospora Tuberculata and Lumnitzera Racemosa against Aedes Aegypti larvae after 24 h.

\begin{tabular}{c|cccc}
\hline Plant species & Part of plant & Regression equation & Chi-square value & LC $_{50}(\mathrm{mg} / \mathrm{ml})$ \\
\hline Tinospora tuberculata & Leaves & $\mathrm{y}=-0.3623 x+5.6422$ & 0.8957 & 0.5778 \\
& Stem & $\mathrm{y}=-0.4287 x+5.9133$ & 0.3968 & 0.7213 \\
& Leaves & $\mathrm{y}=-1.1381 x+4.6715$ & 1.3587 & 1.2833 \\
& Stem & $\mathrm{y}=-1.4967 x+4.6275$ & 1.1192 & 1.1957 \\
\hline
\end{tabular}


were predominantly secondary compounds produced by plants to protect themselves against herbivorous insects (Ibuka et al. 1967).

Pyrethrum, derris, quassia, nicotine, hellebore, anabasine, azadirachtin, $d$-limonene camphor and turpentine were some of the important phytochemical insecticides which were widely used in many countries before the introduction of synthetic organic insecticides (Thangam \& Kathiresan 1990; Bandara 2000). T. tuberculata also contained alkaloid as its secondary metabolite. Secondary metabolites or phytochemicals could be extracted from either the whole plant or from specific parts of the plant that were known to contain a concentration of the desired active chemical. Alkaloids are known as an important secondary metabolites which impart resistance against many insect pests. The resistance to feeding insects by a number of well known alkaloids, the plant sources from which they had come and the insect species deterred, have been uncovered (Essam et al. 2004; Ibuka et al. 1967; Bandara 2000).

Lumnitzera racemosa was considerably less explored compared with other plants, especially herbal plants which were well known for their medicinal properties. That was possibly because mangrove plants were presumed to have no value for medicinal usage and thus very few studies had been conducted to investigate the potential of mangrove plants as an alternative product in medicinal usage. Due to that reason, we would like to explore and understand whether mangrove plants can possibly be used as an alternative to conventional synthetic insecticides, besides the herbal plants. In this study, we have found that the leaf of the $L$. racemosa was more effective that the stem. L. racemosa did have a toxic effect on Ae. aegypti larvae, with leaf extract more toxic compared with the stem extract. However, the active chemical compounds of $L$. racemosa were unknown and for the future research, we plan to investigate the chemical properties of L. racemosa and their role as potential insecticides for controlling the population of Ae. aegypti.

Different mosquito species display different susceptibilities to similar phytochemicals. Thus, this toxicity study might have been much more promising if it had been carried out against different species of mosquitoes. The results of this study however, could be useful in the research for newer, more selective and biodegradable larvicidal compounds. The extracts of these plants can also be combined with synthetic insecticides to obtain more suitable results. For example, leaf and flower extracts of Bougainvillea glabra, exhibit higher insecticidal activity when combined with DDT, Benzene hexachloride and malathion (Thangam \& Kathiresan 1990). It would be interesting to investigate whether the insecticidal and insect repellent compounds in both mangrove and herbal plants contain tannins and alkaloids or other classes of compounds. Further investigations needed are to isolate these compounds using combinations of liquid chromatography, nuclear magnetic resonance spectroscopy and high-pressure liquid chromatography. These techniques have been used by natural product chemists to isolate and determine the structures of interesting molecules.

\section{CONCLUSION}

The results of this study shows promising insecticidal activity from both herbal (T. tuberculata) and mangrove (L. racemosa) plants towards the $3 \mathrm{rd}$ instar Ae. aegypti larvae. T. tuberculata exhibited higher larvicidal toxicity compared to $L$. racemosa. Both plants, T. tuberculata and L. racemosa had the potential to produce alternative insecticides effectively against the $A$ e. aegypti larvae. Further research would have to be done to determine the active compounds from both plants that could be used as larvicides. 


\section{ACKNOWLEDGEMENTS}

We would like to thank the Department of Biological Sciences, University Malaysia Terengganu for financial support, science officers and laboratory assistants who helped in completing this study.

\section{Date of submission: January 2014 \\ Date of acceptance: March 2014}

\section{REFERENCES}

Alkofahi, A, Rupprecht, JK, Anderson, JE, Mclaughlin, JL, Mikolajczak, KL \& Scott, BA 1989, 'Search for new pesticides from higher plants', in Insecticides of plant origin, eds JT Arnason, BJR Philogene \& P Morand, pp. 25-43.

Bandara, KAN P, Kumar, V, Jacobson, U \& Molleyres, LP 2000, 'Insecticidal piperidine alkaloid from Microcos paniculata stem bark', Phytochemistry, vol. 54, pp. 29-32.

Curtis, CF 1986, 'Fact and fiction in mosquito attraction and repulsion', Parasitology Today, vol. 2, pp. 316-318.

Essam, ASS, Deon, C, Mohamed, WFY, Hoda, AW \& Abdel, HM 2004, 'A review of botanical phytochemicals with mosquitocidal potential', Journal of Environmental International, vol. 31, no. 8, pp. 1149-1166.

Finney, DJ 1971, Probit analysis, 3rd edn, New York, Cambridge University Press.

Glubber, D 1989, 'Aedes aegypti and Aedes aegyptiborne disease control in the 1990's: top down or bottom up', American of Tropical Medicine and Hygiene, vol. 40, pp. 571-578.

Ibuka, T, Kitano, M, Watanabe, Y \& Matsui, M 1967, 'Studies on the alkaloids of Menispermaceous plants. Alkaloids of Stephania japonica Miers. 18. Structure of Hasubanonine', Chemical Pharmacology Bulletine (Tokyo).
Jacobson, M 1989, 'Botanical pesticides, past, present and future in insecticides of plant origin', in Proceeding of the American Chemical Society, ed JT Arnason, Washington DC, pp. 1-10.

Ken, O, Zach, AE, Emily, NT, Irma, ASV, Barry, BJ \& Carol, BD 2002, 'Developing arbovirus resistance in mosquitoes', Journal of Insect Biochemistry and Molecular Biology, vol. 32, pp. 1333-1343.

Lee, HL \& Hishamudin, M 1990, 'Nationwide Aedes larval survey in urban towns of Peninsular Malaysia (1988-1989)', Tropical Biomedicine, vol. 7, pp. 185-188.

Premanathan, M, Chandra, K, Bajpai, SK \& Kathiresan, K 1992, 'A survey of some Indian marine plants for antiviral activity', Botanica Marina, vol. 35, pp. 321-324.

Senthil, NS, Kalaivani, K \& Murugan, K 2005, 'Effects of neem limonoids on malaria vector Anopheles stephensi Liston (Diptera: Culicidae)', Acta Tropica Journal, vol. 96, no. 1, pp. 47-55.

Sadasivam, S \& Thayumanavan, B 2003, Molecular host plant resistance to pests, Tamil Nadu Agricultural University Coimbatore, India, pp. 197-239.

Thangam, ST \& Kathiresan, K 1990, 'Synergistic effect of insecticides with plant extracts on mosquito larvae', Tropical Biomedicine, vol. 7, pp. 135-137.

Wong, OP 2001, 'Kajian ketoksikan beberapa ekstrak tumbuhan ke atas larva Aedes aegypti', Thesis, Universiti Kebangsaan Malaysia; and Yap KS, 'Kesan Ketoksikan Ekstrak Kasar Hempedu Beruang. Thottea corymbosa terhadap larvae nyamuk Aedes aegypti', Department of Biological Science, Faculty of Science and Technology, University College of Science and Technology, Malaysia.

World Health Organization 1981, Instruction for determining the susceptibility or resistance of mosquito larvae to insecticide, WHO, Geneva. 